Background Family farms are unique in that children live in the midst of a dangerous workplace. Farm youth continue to experience high rates of injuries and premature deaths as a result of agricultural activities. Increased parental permissiveness has been known to be positively associated with high-risk behaviour in youth, including more frequent sexual activity, elevated pregnancy-rates, and risky driving behaviours. This study explored whether lax-inconsistent or permissive parenting (fathering and mothering) predicts youth unsafe behaviours on the farm.

Methods This study was a part of a larger family-based randomised control intervention study focused on youth farm safety. Pre-intervention data were analysed for 67 youth, their fathers and mothers. Families were recruited through farm publications, youth organisations, local newspapers, farmer referrals, and the Cooperative Extension Network. Two hierarchical multiple regression models were run.

Results Fathers and mothers who practiced lax-inconsistent disciplining were more likely to have youth who indulged in unsafe behaviours on the farm. Lax-inconsistent disciplining by fathers and mothers continued to predict youth unsafe farm behaviours, even after age, youth personality (risk-taking) and father's modelling (of unsafe behaviours) were all taken into account.

Conclusions Findings affirm that farm behaviours belong on the list of adolescent behaviours (like traffic violations) known to be positively influenced by permissive parenting styles. A key implication is that parents play an important role in influencing youth farm safety behaviours, and therefore need to be made the focus of farm safety interventions. Farm safety interventions need to focus not only on safe farm practices, but also promote positive parenting practices, including increased parent-youth communication about safety, consistent parental disciplining practices, increased monitoring and modelling of safe farm behaviours for youth.

\section{IMPLEMENTATION SCIENCE: EVIDENCE-BASED CAR SEAT EDUCATION FOR PARENTS} ${ }^{1,2}$ Mikiko Oono,
Institute of Advanced Industrial Science and Technology, Japan; ${ }^{2}$ Safe Kids Japan, Japan;
${ }^{3}$ Ryokuen Children's Clinic, Japan

\subsection{6/injuryprev-2016-042156.694}

Background According to an annual joint report from Japan Automobile Federation and National Police Agency, Japan, about 40 percent $(40 \%)$ of children under age 6 do not properly use car seats in 2015. Reasons of not using it include parents' emotional opinions such as "I feel sad when a baby resisted staying in a car seat and cried" or "It will be safe if a fellow passenger can tightly hold a baby" and parent's misunderstandings such as "the death rate is not different whether or not a baby is in a car seat" or "It is not absolutely necessary to use a car seat if we do not go a long way." The purpose of this study was to reveal predisposing factors for using a car seat, and by taking them into account, we developed an effective education tool for parents.

Methods We conducted two online surveys from parents aged between 20 and 49 who drove a car with a child at least once a week. The survey respondents were recruited nationwide. The first survey was conducted in November 2013 to find the frequency of car seat use, the type of actions parents usually take when a child resisted staying in a car seat, and the effectiveness of crash test video in increasing parental perceptions of injury severity and self-efficacy. Wilcoxon signed-rank test and Kolmogorov-Smirnov test were used to determine its effectiveness. The second online survey was conducted in February 2014 to find out a specific period of time for a child not to resist staying in a car seat. Based on the results from these two surveys, we developed an animated video and evaluated its effectiveness.

Results One thousand eight people participated in the first survey. When asked the frequency the respondent's child uses a car seat, 69\% said "all the time" and 5\% said "rarely use". About $30 \%$ reported that they let their child out of a car seat when the child resisted staying. Over $30 \%$ said that there are some times when their child sat in a car seat without using safety belts. Finally, we found that crash test videos were effective in increasing parent's perceived severity of injury and self-efficacy. In the second survey, 1002 parents took the survey, and we found that the older the age of children were, the less their frequency of using a car seat. Especially, 25\% of the respondents whose child were over 4 said that the frequency of car seat use was less than half.

Conclusion Based on the results from these surveys, we developed an animated video that showed you the consequences of car crash on a child when not using a car seat properly.

\section{REDUCE ROAD TRAFFIC INJURIES OF CHILDREN RIDING MOTORCYCLES}

Jesus de la Fuente, Amalia Rolloque, Peavy Denisse Azas. Safe Kids Worldwide Philippines, Philippines

\subsection{6/injuryprev-2016-042156.695}

Background Almost 5 million motorcycles are on our roads today. Over 400,000 more are added each year. With 23 Million children (14 years below) in elementary schools, many are transported by motorcycles, often without helmets and using unsafe practices. As of 2014 , over $1 / 3$ of fatal crashes involve motorcycles and there are no laws covering children riders.

Methods Safe Kids Worldwide Philippines, supported by Safe Kids Worldwide, developed a pilot Safe School Zone Project in 2014. First, the public elementary school was selected. The school chosen had the largest student population fronting the most dangerous highway in the country. Mobilisation and organisational activities proceeded covering the parents/teachers association, school principal/teacher- coordinators and the student leaders; followed with the village and the city government officials and finally the regional and national officials. Implemented a baseline study, then periodic project update meetings.

A parallel program for the enactment of the essential City Ordinance and National Legislation was undertaken.

To support the implementation of the law, the Safe Kids Helmet Program was launched in 3 cities of Metro Manila covering 17 schools.

Results With SKWP's active support, Quezon City enacted in April 2015 the landmark ordinance "Regulating the transport of children by means of a motorcycle". A parallel Senate bill was approved in May 2015, with the National law Republic Act No.10666 "Children's Safety on Motorcycles Act of 2015" signed by the President on July 21, 2015. SKWP then launched the Safe Kids Helmet program in the 3 cities of Metro Manila covering 17 schools.

Conclusions With the active collaboration of the key stakeholders and an aggressive advocacy, a seemingly unreachable goal of enacting a National law for Children Safety was achieved. An effective dissemination and implementation program is now essential for a successful Safe Kids Helmet Program. 